\title{
Tourism agglomeration and its impact on social welfare: An empirical approach to the Spanish case
}

\author{
Ainhoa Urtasun ${ }^{\mathrm{a}, *}$, Isabel Gutiérrez ${ }^{\mathrm{b}}$ \\ a Departamento Gestión de Empresas, Universidad Pública de Navarra, Campus Arrosadia, 31006 Pamplona, Spain \\ ${ }^{\mathrm{b}}$ Departamento Economía de la Empresa, Universidad Carlos III de Madrid, C/Madrid 126, 28903 Getafe Madrid, Spain
}

\begin{abstract}
This paper measures two descriptors of tourism namely, its scale and agglomeration level and subsequently evaluates both descriptors according to their direct and joint impacts on the host communities' quality of life. The key constructs for this research are the following: (1) a tourism evaluation function that incorporates the scale and agglomeration of tourism, which is constructed for each one of the 50 Spanish provinces; and (2) a measure of the host communities' quality of life that comprises 12 objective partial indicators and an overall indicator that integrates them all. Results show the existence of carrying capacity frontiers or maximum thresholds that tourist destinations can sustain without damaging the economic, socio cultural, or environmental systems of the communities they belong.
\end{abstract}

Keywords: Communities; Sustainable tourism; Carrying capacity; Spain

\section{Introduction}

What is the impact of tourism on the quality of life of host communities? The aim of this article is to give some quantitative and objective responses to this question. In particular, we first measure two descriptors of tourism development - namely, its scale and level of agglomeration-and subsequently we evaluate both descriptors according to their direct and joint impacts on the host communities' well-being. The social well-being of host regions is measured by 12 partial indicators and an overall indicator of their relative economic, social, cultural, and environmental situation.

The analyses are conducted for the particular case of tourism in Spain, which, with its Mediterranean location, is one of the most important tourist destinations in the world. The results obtained have relevance because

\footnotetext{
*Corresponding author. Tel.: + 34948 169384; fax: + 34948169404 .

E mail addresses: ainhoa.urtasun@unavarra.es

(A. Urtasun), isagut@eco.uc3m.es (I. Gutiérrez).
}

"from the point of view of tourism, Spain is a very rich model to study in terms of the magnitude of its tourist establishment and its great tourist attraction capacity, within the framework of massive consumption patterns" (Monfort \& Ivars, 2001, p. 18). The Spanish economy and society are deeply affected by tourism development. Sinclair describes Spain as a "country whose transition to the ranks of the newly industrializing nations followed the path of a decline in agriculture and rise in tourism and construction activities, which financed the expansion of manufacturing" (Sinclair, 1998, p. 22).

Most of the extensive research on tourism impacts has focused on residents' perceptions of these impacts and the resultant attitudes of residents toward tourism (for a review, see Harrill, 2004). Because findings are mostly based on evidence from survey data in single host communities or in a small number of neighboring areas, they depend on a wide range of idiosyncratic peculiarities, which makes it difficult to synthesize them (Tosun, 2002). Further research is needed to develop a theory of social impacts of tourism, according to King, Pizam, and 
Milman (1993). This research would itself be strengthened by using a tighter theoretical basis and incorporating objective measures of impacts (Harrill, 2004).

Tourism impacts can be managed, controlled, and regulated. In fact, the way tourism is managed will determine whether or not tourism is a sustainable industry. If mismanaged or allowed to expand within short-term objectives, tourism can destroy the integrity of the resources upon which it is built (Mbaiwa, 2003). The development of Spanish mass tourism during the 1960s was a clear example of mismanagement. Mass tourism was conceived in Spain as the ideal antidote to the deep economic crisis in which the country had sunk under the Franco regime's autocratic and protectionist policies. Tourism levels increased without regulation, managed by a centralized policy dominated by macroeconomic and sectorial objectives, and to the detriment of concepts such as equity in the development and the maintenance of a territorial balance. As Cals (1974) summarized it, Spanish tourism grew out of control, oriented to the search for short-term profits within a framework of speculation, while considerations of the environmental and social costs of tourism development were subordinated to economic efficiency.

What does Spanish tourism look like nowadays? Which aspects of the host communities can tourism damage most seriously, and which ones can it improve? Have those regions where mass tourism is more accentuated surpassed their carrying capacities? These are some of the questions that we try to answer in the next sections, which are organized as follows. The second and third sections deal with two key concepts for this research: tourism agglomeration and carrying capacity. Section four briefly describes the data and the methodological approaches used in this article. Sections five and six develop the empirical analyses. Finally, section seven discusses the main conclusions.

\section{The agglomeration phenomenom}

Location is one of the most relevant elements in the development of tourist activities (Carreras, 1995). The local capacity to attract foreign visitors and consumers appears in diversified forms. Locally based tourist resources may include specific natural features of the environment (such as sandy beaches, abrupt mountains, picturesque landscapes, wild forest, or pleasant weather), or man-made features (historic and cultural values or artistic and architectural pieces), or even more practical ones (such as low prices or a high level of tourism facilities), or a special combination of some of these. McIntosh (1977) and Goodall and Asworth (1990) argue that the attractiveness of localities is one of the most powerful elements for the organization of the economic networks of tourism.
Firms concentrate around low-cost and/or highdemand locations (Baum \& Haveman, 1997). In addition to the appeal of a locality, there is a second force driving the clustering of firms: the existence of agglomeration economies, or economies of mutual adjacent location (Weber, 1929). In the context of geographic location, economies of agglomeration include (Baum \& Haveman, 1997) shared infrastructure available to firms that locate close to each other, for example a cluster of hotels around a convention center; and information externalities, both to potential entrants to the industry about existing demand or the feasibility of production at a particular location and to potential clients about the location of supply.

By clustering geographically, firms reduce consumer search costs, which in turn increases demand at a particular location, as with geographic clusters of antique shops, theatres, restaurants, and hotels (Graitson, 1982). As Marshall (1920) argued, agglomeration economies exist in many industries, including manufacturing as well as the retail and service sectors. In those sectors in which consumer search costs are high, however, increases in demand due to information externalities will be especially relevant. In fact, Stahl (1982) argues that firms have an incentive to agglomerate when product traits require visual inspection by consumers, as in the case of restaurants and shops. Dudey (1990) extends this finding of agglomeration to settings where consumers are not searching for product attributes, but rather for low prices.

Several academic studies have already addressed the role of agglomeration in the evolution of the tourism industry, and in particular, the lodging industry-see for example Baum and Mezias (1992), Baum and Haveman (1997), and Ingram and Baum (1997) for the case of the Manhattan hotel industry; and Chung and Kalnins' (2001, 2004) studies of the Texas lodging industry, first in rural areas and then over the entire state. Chung and Kalnins (2004) also provide a literature review of prior agglomeration research, with special emphasis on the retail and service sectors. The authors describe the hotel industry as an economic sector in which "the enticement of agglomeration benefits and resource spillovers likely plays a role in location decisions" (p. 690).

Concentration has its dark side, though, beginning when a maximum threshold of concentration is crossed. Once that point is reached, economic, socio-cultural, and environmental externalities become counterproductive. Therefore, localities attract tourism, and tourist firms attract more tourist firms, in a cumulative process that can change, over-occupy, or even destroy the original attraction of the locality. According to Butler (1980), Prosser (1999), and Glasson, Godfrey, and Goodey (1995), tourism contains the seeds of its own destruction, that is, tourism can kill tourism. Such a result is a quite common aspect of the relevant and contradictory relationship between tourism activities and places. 
The Spanish Mediterranean coast and the Balearic and Canary Islands are clear examples of extreme tourism concentration; and thus, they are good settings in which to examine tourism agglomeration effects. Tourism development in the Mediterranean coast and the islands was extraordinary in its indiscriminate occupation of ground space and in its frequently irrational use of natural resources. During the 1960s and the 1970s, and in the absence of any spatial planning framework, the development of tourism in these areas followed an intensive spontaneous growth model. In fact, tourism agglomeration was a direct consequence of the relative economic underdevelopment of these regions, which received a low level of industrial support from the central government, who tended to favor regions with more industrial dynamism, such as the Basque Country, Catalonia, and Madrid (Méndez, 1993).

\section{Social welfare carrying capacity}

The tourism development cycle models of Butler (1980), Doxey (1975), and Smith (1978) remain popular in examining tourism impacts and community responses (Tosun, 2002). The underlying premise of those models with regard to community impacts is that the host communities' quality of life improves during the initial phases of tourism development but reaches a carrying capacity or level of acceptable change beyond which additional development causes negative changes (Perdue, Long, \& Kang, 1999). According to Gursoy, Jurowski, and Uysal (2002), who recognize that tourism development inevitably changes the residents' quality of life, the application of the concept of carrying capacity has the potential to indicate the degree and direction of change and to aid in the assessment of the extent to which such changes are acceptable.

The concept of carrying capacity has many definitions, but they all have a common denominator: a change in the sign of the impact. Saveriades (2000) describes two schools of thought concerning carrying capacity: one emphasizes the capacity of the tourist destination to absorb tourism before negative impacts are felt by the host community, and the other emphasizes the capacity of the tourist destination to attract and satisfy tourists before negative impacts are felt by the tourists. This paper focuses exclusively on the impacts of tourism on the host communities' quality of life, which we measure by objective partial indicators of social welfare. Since we consider that each dimension of the community's quality of life exhibits a particular carrying capacity for tourism, given a dimension of the communities' quality of life, we define its associated carrying capacity as the maximum threshold of tourism development the community can absorb without a negative impact on that specific dimension of the community's quality of life.

Beyond the literature on economic impacts of tourism, relatively little empirical research has tested in a direct way the effects of tourism development on residents' quality of life (Perdue et al., 1999). Exceptions are Allen, Long, Perdue, and Kieselbach (1988), who examine the effects of tourism development on residents' perceptions of seven dimensions of community life; and Perdue, Long, and Gustke (1991), who examine the effects of tourism development on several objective indicators of residents' quality of life. The findings of the two studies are, however, contradictory. The first generally supports the tourism development cycle theories. Lower to moderate levels of tourism development were perceived by residents as beneficial to the host community quality of life, but, as development continued, resident perceptions of community life declined, particularly as related to public services and opportunities for citizen social and political involvement (Allen et al., 1988). In contrast, the second study finds no social carrying capacity or social disruption curve in their data. Why do their results differ? How well do tourism development cycle theories and their underlying concept of carrying capacity explain the relationship between tourism development and the host community quality of life? As Ko \& Stewart (2002) note, further research is needed to integrate community well-being with tourism development.

\section{Data and methodology}

The two main sources of data used in this study are the online editions of two yearbooks: the Anuario Económico de España (2003) and the Anuario Social de España (2003). These yearbooks are a compendium of statistical information on economic, commercial, and social aspects of the municipalities, provinces, and autonomous regions of Spain. The yearbooks were compiled from official data collected from the Spanish National Institute of Statistics (INE, Spanish acronym) and diverse Spanish ministries. The municipal data included information about each of the 3167 Spanish municipalities with over 1000 inhabitants (approximately $96 \%$ of the total population of Spain) up to 1 January 2002.

The variables selected will be described later, along with the analyses in which they are used. The methodological approaches and their specific objectives are the following: first, we describe each Spanish province's tourism development by a central tendency measure and a dispersion measure; subsequently, we formulate and determine parameter estimates for a model of tourism impacts on the provinces' well-being; finally, we discuss the existence of carrying capacities. 


\section{Empirical analysis on tourism agglomeration}

Given a Spanish province, how extensive is tourism activity, and how is tourism distributed throughout its municipalities? If we wish to abstract from the issue of the province's size, then we can ask, what is the mean tourism activity within each province and how equally is tourism activity within a province distributed around this average. The end-product of this section is a description of each province's tourism development by a two-dimensional vector $\left(\mu_{k}, A_{k}\right)$, where $k$ represents the province, $\mu_{k}$ is its mean tourism activity, and $A_{k}$ measures the level of tourism agglomeration among the municipalities of that province. The variables are the following:

\subsection{Variables}

- $x$ : Tourism Index, whose values, represented by $x_{i k}$, indicate the level of recorded accommodation supply, with $i$ indexing the municipality and $k$ the province. The quantity is expressed relative to the total amount in Spain and refers to the years 1996 and 2001. It is constructed according to the municipal quota of the Spanish "tax on economic activities" (Spanish acronym: IAE) levied on hotels, motels, hostelries, hotel apartments, boarding houses, guest houses, campsites, and seasonal self-catering apartments. The amount levied depends on the number of rooms, the annual occupancy, and the category of the establishment. In 2001, the highest scores on this index for the autonomous regions are Andalusia and Canary Islands, each with $17.3 \%$ of the nationwide total, followed by Balearic Islands and Catalonia, each with $15.3 \%$.

- $y$ : Population, whose values, represented by $y_{i k}$, account for the number of inhabitants of Spanish municipalities in 1996 and in 2001, respectively.

- z: Per Capita Tourism is the variable of interest; its values for a given year are calculated by dividing the tourism supply of municipality $i$ by its population, that is, $z_{i k}=y_{i k} / x_{i k}$.

\subsection{Methodology}

Inequality measures are valuable tools for the study of tourism agglomeration. These measures have been extensively developed in the literature on income distribution (see, for instance, Cowell, 1995), although the concept of inequality has several other meanings and its applicability goes beyond income distributions.

Hannah and Kay (1977) point out that measures of inequality do not always rest on the same conceptual foundations as measures of concentration among firms. But with respect to our study it should be noted that (1) the statistical unit upon which we measure tourism agglomeration is not the firm, but rather the inhabitant of the host community, which is consistent with inequality measures; (2) inequality indices are more suitable than concentration indices for assessing the social welfare impact of tourism agglomeration, since income distribution literature has devoted considerable effort to designing the most appropriate inequality indices for evaluating social welfare; and finally, (3) we need an index sensitive not only to municipalities with large shares of tourism activity but also to those with tiny shares, whose presence can be reflected by an inequality index but not by a concentration index.

Among the wide range of inequality indices (see Cowell, 1995), we choose the Gini coefficient to measure tourism agglomeration, therefore, from now on $A_{k}=G_{k}$. This choice is based on two considerations. (1) The Gini index satisfies the principle of scale independence, a necessary condition since the variable of interest, Per Capita Tourism $\left(z_{i k}\right)$, is given in relative terms. This property is possessed by most inequality indices, with the exception of the variance. (2) The Gini index is easily interpretable. The Gini index is constrained to the range from 0 to 1 , taking the value of 0 for a completely equal distribution, and 1 for a distribution with maximal inequality. Boundedness is a valuable property for measuring inequality, which is violated by other inequality indices such as the logarithmic variance, the variance of logarithms, the Herfindahl index, and some indices of the generalized entropy family. Moreover the underlying function of the Gini coefficient is the Lorenz curve, one of the clearest ways of obtaining a visual picture of inequality in a distribution.

The Gini coefficient $G_{k}$ for the Spanish province $k$ is computed as follows:

$G_{k}=\frac{\mu_{k}-\alpha_{k}}{\mu_{k}}$

where $\mu_{k}=\sum_{i=1}^{n_{k}} z_{i k} x_{i k} / \sum_{i=1}^{n_{k}} x_{i k}$ is the province's mean tourism activity in per capita terms with $\alpha_{k}=\sum_{i=1}^{n_{k}}\left[\gamma_{i k}^{2}-\gamma_{i+1, k}^{2} / \gamma_{1 k}^{2}\right] z_{i k}, \gamma_{i k}=\sum_{h=1}^{n_{k}} x_{h k}$, and $z_{1 k} \leqslant$ $z_{2 k} \leqslant \ldots \leqslant z_{n_{k} k}$ where $n_{k}$ is the number of municipalities of province $k$.

The software DAD 4.2, designed by Duclos, Araar, and Fortin (2004), is applied to make the calculations. In summary, the pair $\left(\mu_{k}, G_{k}\right)$ represents the development of tourism in the province $k$. From (1) it can be shown that Gini coefficient is an area measure. The Gini coefficient is equivalent to $1-2 B$ where $B$ is the area between the Lorenz curve and the $45^{\circ}$ line. ${ }^{1}$

\footnotetext{
${ }^{1}$ To compute the Lorenz curve for each province, first municipalities are ordered by magnitude of tourism per inhabitant, $z_{i k}=y_{i k} / x_{i k}$, starting with the lowest. The $x$ axis shows the cumulative proportion of the total inhabitants of the province per municipality, so the value for the $h$ ranked municipality is $\sum_{i}^{h}{ }_{1} x_{i k} / \sum_{i}^{n_{k}}{ }_{1} x_{i k}$. The $y$ axis shows the cumulative proportion of the total tourism activity of the province
} 


\subsection{Results}

Table 1 shows the values of the pair $\left(\mu_{k}, G_{k}\right)$ for each one of the 50 Spanish provinces, both in 2001 and in 1996. On the one hand, the mean $\mu_{k}$ measures the scale of provincial tourism activity in per capita terms. On the other hand, the Gini index $G_{k}$ measures the level of inequality of the distribution of tourism throughout the municipalities of the province. According to the $t$-test for related samples, neither the mean nor the Gini coefficient of the provinces changed significantly from 1996 to 2001. A comparison among provinces shows that, with respect to provincial tourism scale in per capita terms, Balearic Islands ranked first, and Ciudad Real last. While Balearic Islands are a typical coastal and recreational international destination, Ciudad Real is located in the interior without any special cultural attraction. In 2001, Las Palmas and Santa Cruz de Tenerife, both from Canary Islands, and Alicante showed the highest rates of tourism agglomeration. These provinces are typical coastal destinations, crowded with Spaniards and international tourists. Those provinces with the lowest rates of tourism agglomeration were Álava and Zaragoza, both located in the interior of Spain.

\section{Empirical analysis on the impact of tourism in social welfare}

This section presents some evidence of tourism impacts on the well-being of host communities. With this aim, we determine parameter estimates for the following model of tourism impact on social welfare:

$W_{k}=f\left(T\left(\mu_{k}, G_{k}\right), E_{k}\right)$,

where $W_{k}$ stands for the mean social welfare of province $k$ and is related by the function $f$ to the tourism distribution in that province. $T\left(\mu_{k}, G_{k}\right)$ represents the tourism distribution of province $k$. The literature on income distribution calls $T\left(\mu_{k}, G_{k}\right)$ the "social evaluation function": it ranks income distributions in welfare terms. This paper uses $T\left(\mu_{k}, G_{k}\right)$ to rank tourism distributions according to their scale and level of agglomeration. Given such a function, we can use it to rank any pair of tourism distributions. Finally, $E_{k}$ represents the rest of the variables affecting provincial social welfare. Therefore, the end-product of this section is an estimation of the relationship between the province's tourism development-described by the scale and level of agglomeration of tourism in that provinceand the province's average social welfare, controlling for

(footnote continued)

per municipality, so the value for the $h$ ranked municipality is $\sum_{i 1}^{h} y_{i k} / \sum_{i}^{n_{k}} y_{i k}$. the province's non-tourism economic development. Next, variables are explained in more detail.

\subsection{Dependent variable}

- W: Social Welfare is measured by 12 synthetic objective partial indicators of social welfare in the Spanish provinces during 2001; the Global Social Welfare Index $\left(W^{0}\right)$ is a global well-being indicator formed by the aggregation of the 12 partial indicators. ${ }^{2}$ Table 2 describes the variables included in each one of the 12 partial indicators (a total of 80 variables). The 12 indicators are consistent with those used in their analyses of social welfare by institutions such as the United Nations (UN), the Organization for Economic Co-operation and Development (OECD), and the INE. Each well-being indicator is represented by a ten-level ordinal variable. ${ }^{3}$

\subsection{Independent variables}

- $T\left(\mu_{k}, G_{k}\right)$ : Tourism Evaluation Function. This function jointly considers the scale and agglomeration of tourism in a province during 2001 (as calculated in the previous section). Both the mean and the variation of tourism activity should be included when estimating tourism impacts on a wide region, as for instance a province, that is compounded by various communities, in this case municipalities, across which tourism is not equally distributed. Moreover, the joint consideration of both measures provides a more complete and accurate picture of the real provincial tourism distribution than each of those measures would provide separately, as neither of the two measures informs about the other. We use $T\left(\mu_{k}, G_{k}\right)=\mu_{k}\left(1-G_{k}\right)$, which is a social evaluation function of recognized properties in income distribution research (Lambert, 2001). Given two distributions with the same mean, this function gives a higher rank to the one that is more equally distributed. In the same way, given two distributions with the same degree of inequality, this function gives a higher rank to the one with the greater mean. Table 3 shows Pearson correlation coefficients of the provincial mean tourism $\mu_{k}$ and the provincial tourism agglom-

\footnotetext{
${ }^{2}$ The aggregation of the original variables into their correspondent partial indicator is carried out by weighting each original variable according to its correlation with the rest of the original variables and with the partial indicator in an iterative process that ends when a convergence point is reached. The aggregation of the 12 partial indicators into a global indicator follows the same process.

${ }^{3}$ This numerical scale was derived by transforming an originally continuous variable into a provincial series of index numbers relative to 100 , which corresponds to the national mean, and then, splitting the series into an interval scale variable, such that the national mean coincides with the boundary between levels 5 and 6 .
} 
Table 1

Tourism distribution in the Spanish provinces

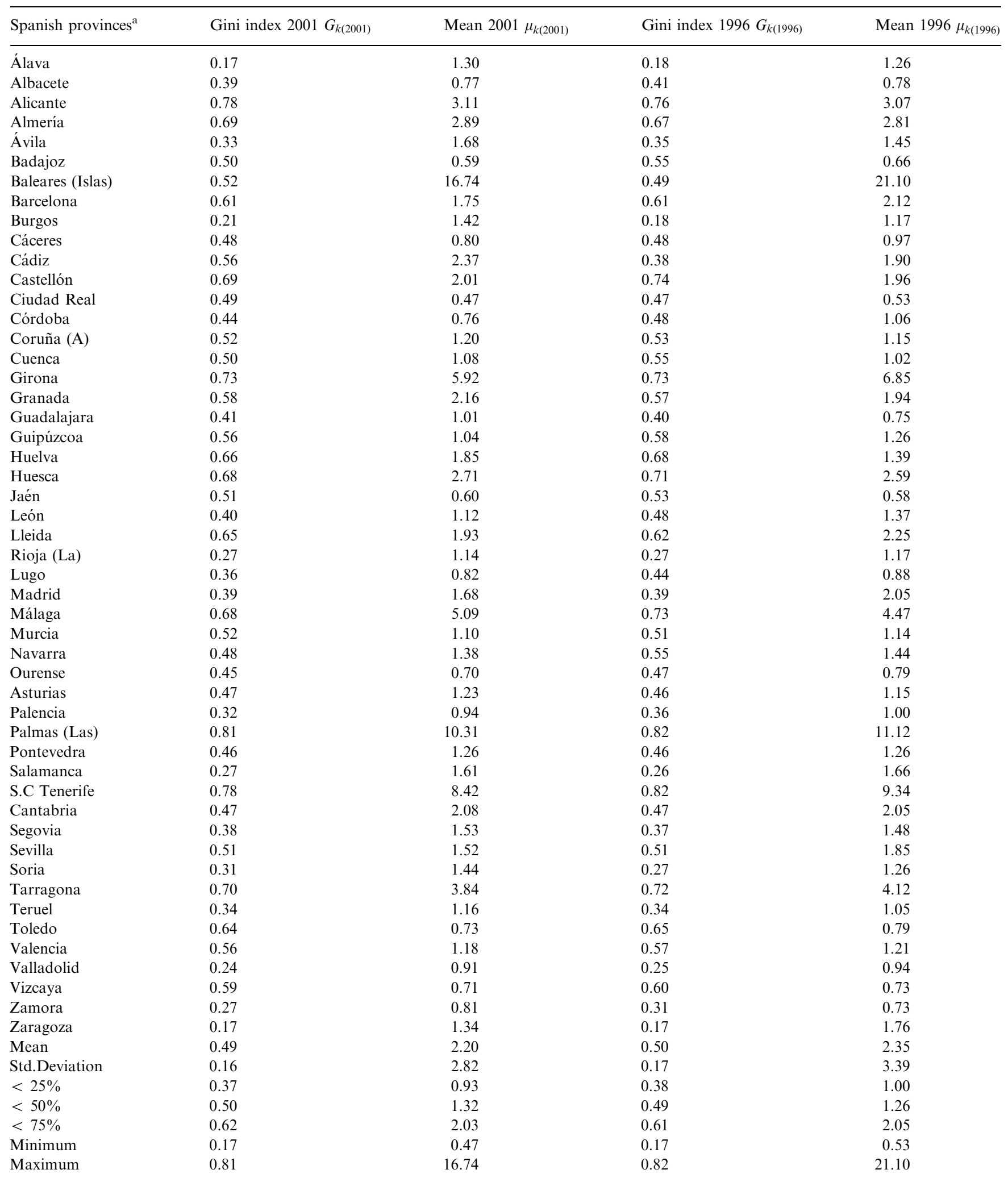

Source: Anuario Económico de España (2003) and Anuario Social de España (2003).

${ }^{\text {a }}$ Provinces named in Spanish 
Table 2

Description of the 12 partial indicators of Social Welfare $(W)$

\section{$W^{1}$ Income Index}

$W^{2}$ Health Index

$W^{3}$ Health Service Index

$W^{4}$ Education Attainment Index

$W^{5}$ Cultural and Leisure Option Index

$W^{6}$ Employment Attainment Index

$W^{7}$ Employment Quality Index

$W^{8}$ Housing and Household Equipment Index

$W^{9}$ Accessibility and Road Security Index

$W^{10}$ Coexistence and Social Participation Index

$W^{11}$ Citizen Security Index

$W^{12}$ Environmental Quality Index
Indicator of: (1) Per capita disposable household income in the province.

Synthetic indicator of the average degree of health in the Spanish provinces, constructed from: (2) Life expectancy, (3) mortality rate, (4) neonatal mortality, (5) average of suicides, (6) deaths from drug consumption, (7) hospitalized patients, (8) cancer patients, (9) AIDS patients, (10) cases of infectious, and (11) rate of disabled people.

Synthetic indicator for health care provision in the Spanish provinces, constructed from: (12) Average distance to the nearest public hospital, (13) rate of hospital beds, (14) rate of high technology medical services supplied by hospitals, (15) rate of licensed physicians, (16) rate of registered nurses, and (17) rate of beds in senior care centers.

Synthetic indicator of the average education level of the Spanish provinces, from 4 variables of educational level of inhabitants: (18) Rate of inhabitants with high school degree, (19) rate of inhabitants with university degree, (20) rate of adolescents attending high school, and (21) rate of university age inhabitants attending university; and 4 variables of cultural level of the inhabitants: (22) newspaper readership, (23) persons attending cinema, (24) internet usership, and (25) rate of library users.

Synthetic indicator for cultural and leisure supply, with 9 variables of artistic, cultural and recreational attractions: (26) Rate of museums, (27) performance halls, (28) music and dancing resources, (29) number of cinema spectators, (30) rate of bullfights, (31) traditional festivals, (32) bars and restaurants, (33) shopping and leisure centers, and (34) senior citizen centers; and 2 variables for sporting leisure: (35) Sports facilities, and (36) establishments of outdoor recreation. Indicator of labor market conditions: (37) Unemployment rate, (38) youth unemployment rate, and (39) employment rate.

Synthetic indicator of quality of life in the workplace: (40) Rate of serious and fatal accidents in the workplace, (41) rate of serious occupational illness requiring sick leave, (42) rate of temporary, or unstable job contracts, (43) rate of unemployment coverage, (44) rate of enrolment in training courses for the unemployed, and (45) rate of infant care subsidies.

Synthetic indicator comprising 4 variables of housing accessibility: (46) Rate of finished state subsidized housings, (47) housing average price per $\mathrm{m}^{2}$, (48) rate of households with housing $>100 \mathrm{~m}^{2}$, and (49) rate of households with second housing; and 11 variables of household equipment: (50) Rate of households with satellite dish, (51) vacuum cleaner, (52) car, (53) internet access, (54) fridge freezer, (55) dishwasher, (56) microwave, (57) personal computer, (58) mobile phone, (59) two or more TVs, and (60) video player.

Synthetic indicator of: (61) Average distance to the main town in an area, (62) rate of length of toll ways and limited access highways, (63) rate of length of two lane highways, (64) passengers in commercial airports, (65) trips on rail routes, and (66) total road accident victims.

Synthetic indicator including: (67) Rate of marital break ups, (68) large families, (69) rate of active associations, (70) rate of participants in non authorized demonstrations, and (71) abstentionism in the state elections in 2000.

Synthetic indicator including: (72) Rate of crimes, (73) rate of arrested persons, (74) rate of police intervention in actions against the natural surroundings and the environment, (75) deadly attacks, (76) terrorist death threats, and (77) rate of street violence.

Synthetic indicator including 2 variables of environment quality affecting households: (78) Rate of dwellings with little green area and (79) rate of dwellings with low standards of cleanliness in the streets; and 1 variable of environmental quality affecting natural surroundings: (80) Rate of woodland surface area affected by fire. eration $G_{k}$, taken separately, with each one of the well-being indicators, including the global indicator. Although preliminary, the observed correlations are consistent with the underlying assumptions in $\mu_{k}\left(1-G_{k}\right)$. As observed in the table, the scale of tourism has a significantly positive effect on the Global Social Welfare Index $\left(W^{0}\right)$ and on two partial indicators of well-being: the Cultural and Leisure Option Index $\left(W^{5}\right)$ and the Employment Index $\left(W^{6}\right)$. The agglomeration effect is only significantly positive on the Accessibility and Road Security Index ( $\left.W^{9}\right)$. In contrast, the agglomeration effect is significantly negative on four well-being indicators: the Health
Service Index $\left(W^{3}\right)$, the Coexistence and Social Participation Index $\left(W^{10}\right)$, the Citizen Security Index $\left(W^{11}\right)$, and the Environmental Quality Index $\left(W^{12}\right)$; while the scale effect is significantly negative only for the Environmental Quality Index $\left(W^{12}\right)$.

- $E\left(\mu_{k}^{\prime}, G_{k}^{\prime}\right)$ : Economic Evaluation Function. Additionally, the model in (2) takes into account the impact on social welfare made by the province's level of development in economic activities other than tourism, by including the variable $E\left(\mu_{k}^{\prime}, G_{k}^{\prime}\right)$. The values of that variable are calculated and expressed in the same way as the values of the variable Tourism Evaluation Function, that is, $E\left(\mu_{k}^{\prime}, G_{k}^{\prime}\right)=\mu_{k}^{\prime}\left(1-G_{k}^{\prime}\right)$, where $\mu_{k}^{\prime}$ is the per capita 
mean of economic activities other than tourism in the province $k$, and $G^{\prime}$ is the corresponding Gini index, both dated from 2001. It is interesting to observe that Gini indices in economic activities other than tourism activity are significantly below Gini indices corresponding to tourism, suggesting that agglomeration is a distinctive feature of tourism development. The Gini index values of economic activities other than tourism are not shown in the paper.

\subsection{Methodology}

The starting approximation to the model in (2) is formulated as follows:

$W_{k}^{j}=\beta_{0}+\beta_{1} T_{k}+\beta_{2} E_{k}+\beta_{3}\left(T_{k} \times E_{k}\right)+\xi_{k}$,

where $k$ denotes province and $j$ is one particular Social Welfare indicator. $T_{k}=\mu_{k}\left(1-G_{k}\right)$ and $E_{k}=\mu_{k}^{\prime}(1-$ $\left.G_{k}^{\prime}\right)$ are the Tourism Evaluation Function and the Economic Evaluation Function, respectively. $\beta_{1}$ measures the relationship between $T_{k}=\mu_{k}\left(1-G_{k}\right)$ and each one of the various social welfare indicators. $\beta_{3}$ the interaction coefficient - measures the importance of the interrelationship between tourism activity and other economic activities in affecting social welfare. Stepwise multiple regression methodology (Cramer, 2003) provides a parsimonious specification of the model in (3) that maximizes accuracy with an optimally reduced number of predictor variables.

\subsection{Results}

Table 4 shows ordinary least square (OLS) estimations, as well as fit statistics, and diagnostic tests for the final models selected by the stepwise method for each one of the various welfare indicators. Following this method, the regressions of the Educational Attainment Index $\left(W^{4}\right)$, the Employment Quality Index $\left(W^{7}\right)$, and the Housing and Household Equipment Index $\left(W^{8}\right)$ are not run because the Tourism Evaluation Function $T_{k}$, taken both by itself and in interaction with $E_{k}$, fails to explain a significant proportion of the variance in these three welfare indicators.

To ensure that the assumptions of the OLS method were met, we tested for multicollinearity and heteroskedasticity and found neither to be a problem. First, multicollinearity is guarded against as no variance inflation factor (VIF) exceeds 2 and no condition number exceeds 3. Prior to the estimations, the independent variables were centered, a procedure recommended to reduce the problem of multicollinearity in the presence of interaction terms (Aiken \& West, 1991). Second, White's $\chi^{2}$ test for violation of homoskedasticity assumptions was executed and no pattern of heteroskedasticity was detected. In addition to OLS 
Table 4

OLS estimates of tourism impacts on social welfare

\begin{tabular}{|c|c|c|c|c|c|c|c|}
\hline \multirow[t]{2}{*}{ Social welfare indices $W^{j}$} & \multicolumn{4}{|c|}{ Estimated coefficients } & \multicolumn{3}{|c|}{ Diagnosis tests } \\
\hline & Constant & $V_{k}$ & $E_{k}$ & $V_{k} \times E_{k}$ & $R$ Square & $\begin{array}{l}\text { Condition } \\
\text { Index }\end{array}$ & $\begin{array}{l}\text { White's } \\
\text { test }^{\mathrm{a}}\end{array}$ \\
\hline$W^{0}$ Global Social Welfare Index & $5.98 * * *(.30)$ & $.64 * *(.20)$ & $4.63 * * *(.57)$ & $1.95 *(.84)$ & .65 & 2.70 & 2.75 \\
\hline$W^{1}$ Income Index & $5.46 * * *(.23)$ & $.58 * * *(.16)$ & $4.84 * * *(.44)$ & $1.52 *(.65)$ & .77 & 2.70 & 4.9 \\
\hline$W^{2}$ Health Index & $5.13 * * *(.39)$ & & $2.71 * * *(.75)$ & $2.53 *(1.10)$ & .21 & 2.68 & 3.1 \\
\hline$W^{3}$ Health Service Index & $5.44 * * *(.29)$ & $.48+(.27)$ & $2.89 * * *(.60)$ & & .35 & 1.01 & 0.15 \\
\hline \multicolumn{8}{|l|}{$W^{4}$ Educational Attainment Index } \\
\hline$W^{5}$ Cultural and Leisure Option Index & $6.00 * * *(.33)$ & $.73 * *(.22)$ & $4.04 * * *(.63)$ & $2.52 * *(.92)$ & .54 & 2.70 & 3.55 \\
\hline$W^{6}$ Employment Index & $5.44 * * *(.22)$ & $.73^{* * * *}(.20)$ & $3.24 * * *(.45)$ & & .57 & 1.01 & 0.4 \\
\hline \multicolumn{8}{|l|}{$W^{7}$ Employment Quality Index } \\
\hline \multicolumn{8}{|l|}{$W^{8}$ Housing and Household Equipment } \\
\hline$W^{9}$ Accessibility and Road Security Index & $4.85^{* * *}(.41)$ & & & $2.29 *(1.01)$ & .09 & 1.94 & 1.45 \\
\hline $\begin{array}{l}W^{10} \text { Coexistence and Social Participation } \\
\text { Index }\end{array}$ & $6.34 * * *(.39)$ & $.78 * *(.29)$ & & $3.05 * *(.95)$ & .25 & 1.95 & 0.7 \\
\hline $\begin{array}{l}W^{11} \text { Citizen Security and Environmental } \\
\text { Safety Index }\end{array}$ & $6.42 * * *(.29)$ & & & $2.96 * * *(.75)$ & .25 & 1.94 & 0.65 \\
\hline$W^{12}$ Environmental Quality Index & $5.50 * * *(.35)$ & $.57+(.32)$ & $2.96 * * *(.72)$ & & .29 & 1.01 & 5.75 \\
\hline
\end{tabular}

*** $p<0.001 ; * * p<0.01 ; * p<0.05 ;+p<0.10$.

Standard Errors of estimated parameters are in parentheses. $N=50$.

${ }^{\mathrm{a}} \chi^{2}=7.81$ critical value for $\alpha=.05$ and $d f=3$.

estimations, ordinal estimations (McCullagh, 1980) were carried out, although those results are not shown in this paper. The ordinal results closely match and thus strengthen our confidence in the robustness of the reported OLS results.

Interestingly, the Tourism Evaluation Function $T_{k}$, taken either by itself or in interaction with $E_{k}$, has a significant impact on the Global Social Welfare Index $\left(W^{0}\right)$, as well as on the following nine partial indicators: the Income Index $\left(W^{1}\right)$, the Health Index $\left(W^{2}\right)$, the Health Service Index $\left(W^{3}\right)$, the Cultural and Leisure Option Index $\left(W^{5}\right)$, the Employment Index $\left(W^{7}\right)$, the Accessibility and Road Security Index $\left(W^{9}\right)$, the Coexistence and Social Participation Index $\left(W^{10}\right)$, the Citizen Security Index $\left(W^{11}\right)$, and Environmental Quality Index $\left(W^{12}\right)$. The fact that $T_{k}$ had a significant impact on ten of thirteen welfare indices seems to validate the role of $T_{k}$ as a social evaluation function for tourism.

The ten finally selected regression models can be classified according to whether or not the slope $\partial W_{k}^{j} / \partial T_{k}$ depends on $E_{k}$ - the province's level of development in economic activities other than tourism. (1) Social welfare models whose slope with respect to $T_{k}$ is unaffected by $E_{k}$, that is, in which the estimated coefficient on the interaction term is not significant. This is the case for $W^{3}, W^{6}$ and $W^{12}$. To be precise, we found that regardless of the province's non-tourism economic development, increases in the Tourism Evaluation Function $\left(T_{k}\right)$ are always associated with increases in the Health Service Index $\left(W^{3}\right)$ and the Employment Index
$\left(W^{6}\right)$, but with decreases in the Environmental Quality Index $\left(W^{12}\right)$. (2) Social welfare models whose slope with respect to $T_{k}$ varies with $E_{k}$, that is, in which the estimated coefficient on the interaction term is significant. This is the case for $W^{0}, W^{1}, W^{2}, W^{5}, W^{9}, W^{10}$, and $W^{11}$.

A tourism carrying capacity threshold is a value of $E_{k}$-the province's level of development in economic activities other than tourism-at which $\partial W_{k}^{j} / \partial T_{k}$ undergoes a significant change from a positive to a negative value. To probe significant changes in the sign of $\partial W_{k}^{j} / \partial T_{k}$ depending on $E_{k}$, we follow Friedrich's (1982) approach. Tourism carrying capacities, as so defined, are found in the Global Social Welfare Index $\left(W^{0}\right)$, the Income Index $\left(W^{1}\right)$, the Cultural and Leisure Option Index $\left(W^{5}\right)$, the Coexistence and Social Participation Index $\left(W^{10}\right)$, and the Citizen Security Index $\left(W^{11}\right)$. To be precise, the tourism impact on these five indices is positive as long as the level of non-tourism economic development has not surpassed a certain lower threshold. But the tourism impact can be negative if the development in economic activities other than tourism has surpassed a certain upper threshold. Finally, the results for the Health Index $\left(W^{2}\right)$ and Accessibility and Road Security Index $\left(W^{9}\right)$ are somewhat unexpected, since $\partial W_{k}^{j} / \partial T_{k}$ changes from negative to positive as $E_{k}$ increases.

Therefore, the estimations provide three important findings. First, tourism impacts vary significantly depending on the social welfare indicator considered: 
Table 5

Estimated thresholds of social welfare carrying capacity with regard to tourism

SOCIAL WELFARE INDICES $W^{j}$

$W^{0}$ Global Social Welfare Index
$W^{1}$ Income Index
$W^{2}$ Health Index
$W^{3}$ Health Service Index
$W^{5}$ Cultural and Leisure Option Index
$W^{6}$ Employment Index
$W^{9}$ Accessibility and Road Security Index
$W^{10}$ Coexistence and Social Participation Index
$W^{11}$ Citizen Security Index
$W^{12}$ Environmental Quality Index

SIGN OF $\partial W^{j} / \partial T$ DEPENDING ON $E$

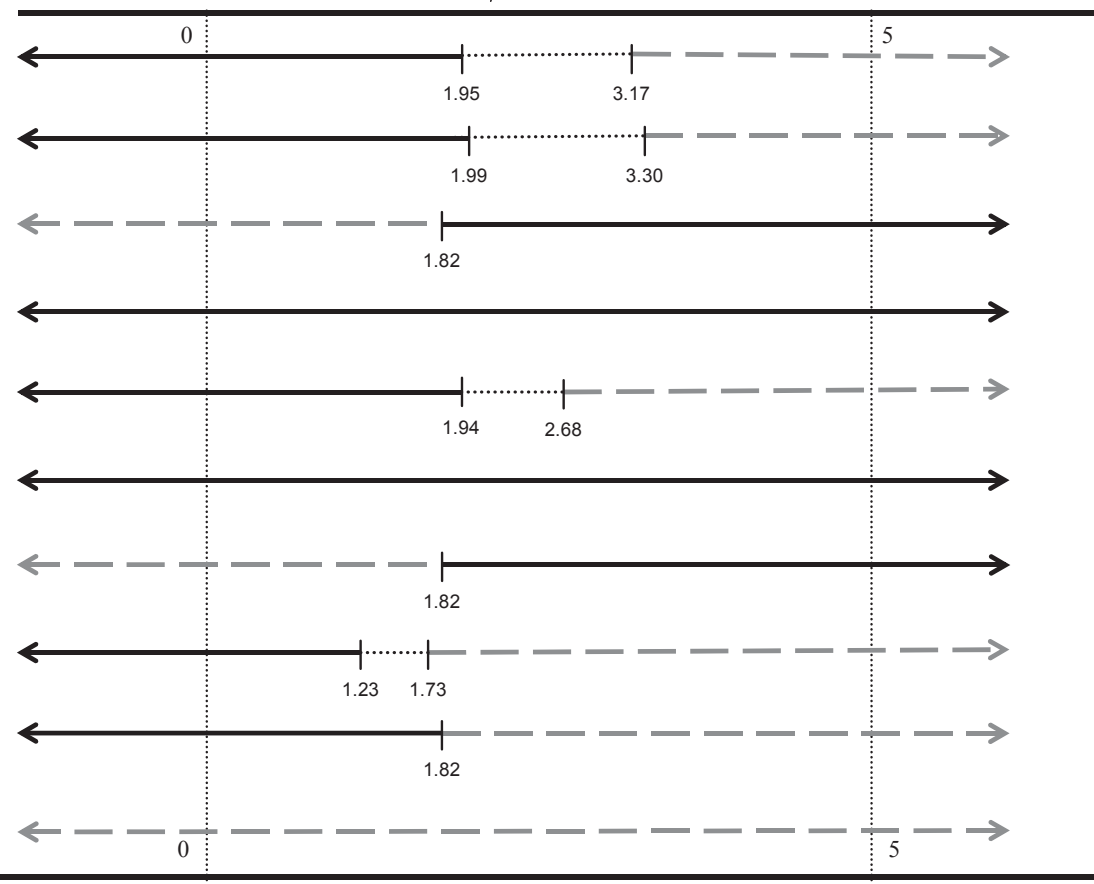

NO SIGNIFICANT TOURISM IMPACT;

- NEGATIVE TOURISM IMPACT while some social welfare indicators show carrying capacity thresholds, others do not. Table 5 shows the exact values of the carrying capacity thresholds found for each of the welfare indicators. Second, we prove that certain measure that jointly considers the scale and agglomeration of tourism in a province has a significant relationship with the average social welfare of that province. And third, tourism impacts on the province's average social welfare depend on the province's level of non-tourism economic development.

\section{Discussion and conclusion}

This article analyzes the impact of tourism on several objective dimensions of the host regions' quality of life. The analyses show that three distinct aspects of tourism produce jointly significant impacts on the host communities' well-being-namely, (1) the scale of tourism, measured in per capita terms, (2) the unequal distribution of tourism across localities, that is, the agglomeration propensity, and (3) the level of development of the host communities in economic activities other than tourism. To the best of our knowledge, this is the first time that these features and their joint effects have been examined.
Accordingly to our results, tourism impacts on the residents' quality of life vary depending on which dimension of quality of life is considered. Our tourism evaluation function, which gives a higher rank to tourism distributions with higher means and lower agglomeration levels, was positively related with medical services and employment, regardless of the level of other economic activities; but no impact is found on employment quality. In contrast, we found that the tourism evaluation function always have a negative impact on environment quality. Contrary to Perdue et al. (1991), who found a positive tourism impact on per student education expenditures, we have not found any significant tourism impact on the educational attainment of the host regions. Likewise, the impact on the residents' housing conditions is not significant. Perdue et al. (1991) also found that per capita income and the quality of available health care facilities increase with increasing levels of tourism. With regard to per capita income, as well as to culture and leisure services, coexistence, and citizen security, our results show that tourism impacts are positive in regions with a low level of development in economic activities other than tourism, but negative in regions with a high level of non-tourism economic development. This pattern is also observed in overall social welfare terms. Per capita income, cultural and leisure services, and social welfare in overall terms 
exhibit, on the other hand, superior thresholds of carrying capacity than coexistence and citizen security.

In conclusion, according to our analyses, various dimensions of residents' quality of life exhibit a carrying capacity level or maximum threshold that a region can absorb without a negative impact on its residents' quality of life. In contrast, no social carrying capacity was found by Perdue et al. (1991), who observed relationships monotonically increasing or decreasing with levels of tourism. Perhaps the reason they obtained constant effects was that the authors did not take into account either the agglomeration effect of tourism or its interaction with other economic activities in the region.

Finally, it is important to recognize the design limitations of this research in the study of such a controversial issue. First, the ideal research design for a precise evaluation of tourism social impacts would be a panel data set, since panel data enable to account for unobserved and temporal effects. Due to the unavailability of data, this research uses the alternative design most often applied: the comparison of regions in different stages of development. Second, because of the lack of reliable data on tourism demand, this paper explores the supply side of tourism, contrary to most papers on tourism impacts that cover the demand side of tourism. Finally, this research has examined tourism impacts on the average social welfare of the inhabitants of an entire region; further research in tourism impacts on residents' social welfare should investigate the effects that an unequal distribution of tourism throughout the localities of a region has on the degree of inequality observed in the social welfare levels of these localities.

\section{Acknowledgments}

The authors thank the Spanish Commission for Science and Technology (project SEC2003-03797) for its financial support.

\section{References}

Aiken, L. S., \& West, S. G. (1991). Multiple regression: Testing and interpreting interactions. Newbury Park, CA: Sage.

Allen, L. R., Long, P. T., Perdue, R. R., \& Kieselbach, S. (1988). The impact of tourism development on residents' perceptions of community life. Journal of Travel Research, 27, 1621.

Anuario Económico de España (2003). Barcelona: Servicio de Estudios de la Caixa. http://www.estudios.lacaixa.comunicacions.com

Anuario Social de España (2003). Barcelona: Fundación la Caixa. http://www.anuarisoc.lacaixa.comunicacions.com

Baum, J. A. C., \& Haveman, H. A. (1997). Love thy neighbor? Differentiation and agglomeration in the Manhattan hotel industry, 1898 1990. Administrative Science Quarterly, 42, 304338 .

Baum, J. A. C., \& Mezias, S. J. (1992). Localized competition and organizational failure in the Manhattan hotel industry, 18981990. Administrative Science Quarterly, 37, 580604.
Butler, R. W. (1980). The concept of a tourist area cycle of evolution: Implications for management of resources. Canadian Geographer, 24, 512.

Cals, J. (1974). Turismo y politica turística en España. Una aproxima ción. Barcelona: Ariel.

Carreras, C. (1995). Mega events: Local strategies and global tourist attractions. In A. Montanari, \& A. M. Williams (Eds.), European tourism: Regions, spaces and restructuring (pp. 193 205). Chiche ster, England: Wiley.

Chun, W., \& Kalnins, A. (2001). Agglomeration effects and performance: A test of the Texas lodging industry. Strategic Management Journal, 22, 969988.

Chun, W., \& Kalnins, A. (2004). Resource seeking agglomeration: A study of market entry in the lodging industry. Strategic Manage ment Journal, 25, 689699.

Cowell, F. A. (1995). Measuring Inequality (2nd ed). Hemel Hempstead, UK: Harvester Wheatsheaf.

Cramer, D. (2003). Advanced quantitative data analysis. Maindehead, PA: Open University Press.

Doxey, G.V. (1975). A causation theory of visitor resident irritants' methodology and research inferences. Proceedings of the Sixth Annual Conference of the Travel Research Association. San Diego, CA: Travel and Tourism Research Association (pp. 195 198).

Duclos, Y.I., Araar, A., \& Fortin, C. (2004). DAD: A software for distributive analysis/analyse distributive, MIMAP programme (Version 4.4). Québec, Canada: International Develo pment Research Centre, Government of Canada, and CIRPÉE, Université Laval.

Dudey, M. (1990). Competition by choice: The effect of consumer search on firm location decisions. American Economic Review, 80, 10921104.

Friedrich, R. J. (1982). In defense of multiplicative terms in multiple regression equations. American Journal of Political Science, 26(4), 797833.

Glasson, J., Godfrey, K., \& Goodey, B. (1995). Towards visitor impact management: Visitor impacts, carrying capacity and management responses in Europe's historic towns and cities. Aldershot, England: Avebury.

Goodall, B., \& Asworth, G. (1990). Marketing in the tourism industry. London: Routledge.

Graitson, D. (1982). Spatial competition à la Hoteling: A selective survey. Journal of Industrial Economics, 31, 1325.

Gursoy, D., Jurowski, C., \& Uysal, M. (2002). Resident Attitudes. A structural modelling approach. Annals of Tourism Research, 29(1), 79105.

Hannah, L., \& Kay, J. A. (1977). Concentration in British industry: Theory, measurement and the UK experience. London: MacMillan.

Harrill, R. (2004). Residents' attitudes toward tourism development: A literature review with implications for tourism planning. Journal of Planning Literature, 18(3), 251266.

Ingram, P., \& Baum, J. A. C. (1997). Chain affiliation and the failure of Manhattan hotels, 1898 1980. Administrative Science Quarterly, 41, 68101.

King, B., Pizam, A., \& Milman, A. (1993). Social impacts of tourism: Host perceptions. Annals of Tourism Research, 20(4), 650665.

Ko, D. G., \& Stewart, W. P. (2002). A structural equation model of residents' attitudes for tourism development. Tourism Manage ment, 23, 521530.

Lambert, R. J. (2001). The distribution and redistribution of income (3rd ed). Manchester and New York: Manchester University Press.

Marshall, A. (1920). Principles of economics (8th ed). London: Macmillan.

Mbaiwa, J. E. (2003). The socio economic and environmental impacts of tourism in the Okavango Delta, northwestern Botswana. Journal of Arid Environments, 54(2), 447468. 
McCullagh, P. (1980). Regression models for ordinal data. Journal of the Royal Statistical Society. Series B (Methodological), 42(2), 109142.

McIntosh, R. W. (1977). Tourism: Principles, practices and philoso phies. Columbus, OH: Grid.

Méndez, R. (1993). Desequilibrios territoriales y políticas de interven ción. In R. Méndez, \& F. Molinero (Eds.), Geografía de España (pp. 639 667). Barcelona: Ariel.

Monfort, V. M., \& Ivars, J. A. (2001). Towards a sustained competitiveness of Spanish tourism. In Y. Apostolopoulos, P. Loukissas, \& L. Leontidou (Eds.), Mediterranean tourism: Facets of socio economic development and cultural change (pp. 17 38). London, New York: Routledge.

Perdue, R. R., Long, P. T., \& Gustke, L. D. (1991). The effects of tourism development on objective indicators of local quality of life. Proceedings of the 22nd Annual TTRA International Conference. Salt Lake UT: Travel and Tourism Research Association (pp. 191 201).

Perdue, R. R., Long, P. T., \& Kang, Y. S. (1999). Boomtown tourism and resident quality of life: The marketing of gaming to host community residents. Journal of Business Research, 44, 165177.

Prosser, R. (1999). Societal change and the growth in alter native tourism. In E. Cater, \& G. Lowman (Eds.), Eco tourism: A sustainable option, (pp. 19 37). New York: John Wiley \& Sons.

Saveriades, A. (2000). Establishing the social tourism carrying capacity for the tourist resorts of the east coast of the Republic of Cyprus. Tourism Management, 21, 147156.

Sinclair, M. T. (1998). Tourism and economic development: A survey. The Journal of Development Studies, 34(5), 151.

Smith, V. (1978). Eskimo tourism: Micro models and marginal men. In V. Smith (Ed.), Host and guests (pp. 51 70). Oxford: Blackwell.

Stahl, K. (1982). Differentiated products, consumer search, and locational oligopoly. Journal of Industrial Economics, 31(1/2), 97113.

Tosun, C. (2002). Host perceptions of impacts. A comparative tourism study. Annals of Tourism Research, 29(1), 231253.

Weber, A. (1929). Theory of the location of industries. Chicago: University of Chicago Press. 